\title{
Herpes Virus And Periodontal Disease
}

\author{
Sravya Chedalawada ${ }^{1}$, Raja Babu P2 , J agadish Reddy ${ }^{3}$, Vikram Reddy $G^{4}$
}

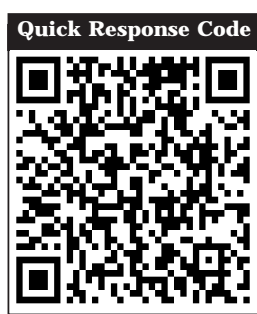

doi: 10.5866/2016.8.10046

${ }^{1}$ Post Graduate student

${ }^{2}$ HOD\&Professor, M.D.S

${ }^{3 \& 4}$ Reader, M.D.S

Department of Periodontics,

Kamineni Institute of Dental Sciences.

Narketpally, Nalgonda, Telangana.

\section{Article Info:}

Received: J anuary 7, 2016

Review Completed: February 6, 2016

Accepted: March 8, 2016

Available Online: May, 2016 (www.nacd.in)

C NAD, 2016 - All rights reserved

\section{Email for correspondence:}

drsravyabds@gmail.com

\begin{abstract}
:
Periodontitis is a chronic inflammatory disease which leads to tissue destruction and alveolar bone loss. Besides oral bacteria, various risk factors play a role in the progression of periodontal disease. Various studies have reveal ed the crucial role of viruses in initiation and progression of the periodontal disease by stimulating the overgrowth of potential periopathogens, modulating the host response, causing immunosuppression and having direct cytopathic effects on periodontal tissues leading to destructive periodontal disease. This review explains the potential role of herpes viruses in etiol ogy of periodontal disease.
\end{abstract}

Key words: Herpes virus, Periodontitis, Host response.

\section{Introduction:}

Periodontitis is a chronic inflammatory disease initiated by an infection of oral microorganisms and involves humoral and cellular characteristics of host response and a variety of disease modulating environmental factors. Although previous research on periodontal disease has concluded that putative pathogenic bacteria in dental plaque and their products are etiological agents for periodontal disease certain differences in loss of periodontal attachment, alveolar bone and limited gingival inflammation with comparable levels of risk factors have galvanized efforts to find additional etiologic factors for periodontitis. ${ }^{1}$
Non-bacterial microorganisms that are found in plaque include viruses, mycoplasma, yeasts and protozoa. Recently, it was suggested that certain viruses might also influence the development and severity of periodontal diseases, though the cause of gingivitis and periodontitis is credited to bacteria colonizing tooth surfaces and initiating the major mechanisms of periodontal destruction. ${ }^{2}$ Viruses can also interfere with immune responses through immune modulators encoded within viral genomes, which include proteins that regulate antigen presentation, function as cytokines or cytokine antagonists, inhibit apoptosis \& interrupt the complement cascade. ${ }^{3}$ Thus, a situation of viralbacterial interaction could occur in the oral cavity 
without a denial of the argument for a major etiological role of bacteria in human periodontal disease. Hence, the development of periodontal disease depends upon the cooperative interaction among specific pathogenic bacteria, viruses and tissue destructive inflammatory mediators. ${ }^{4}$

\section{History of viral etiology:}

In 1996, Contreras observed an increased association between Herpes Simplex Virus (HSV) and periodontitis. ${ }^{5}$ Parra and Slots demonstrated a significant prevalence for Human Cytomegalovirus (HCMV) and Epstein - Barr virus (EBV) in the subgingival plaque of adult periodontitis patients when compared with healthy/gingivitis patients. ${ }^{6}$ Thus, a new era in periodontology was ushered and the possible involvement of viruses in periodontal disease gained more attention. Soon, numerous studies evaluating the association, prevalence, and possible pathogenic role of herpes viruses in destructive periodontal disease followed.

\section{Hypothesis on etiology of periodontal diseases:}

Periodontal diseases are complex infectious diseases that can be attributed to multiple viral agents which in turn induce host immune responses. Studies on a viral cause for periodontitis marked a turning point in periodontal research, which until recently was centred almost exclusively on a bacterial etiology (Figure 1).

\section{Herpes viruses:}

Herpes viruses are usually found in infected secretions such as saliva, may cause oral mucosa lesions during the primary infections, are capable of indefinite latency, and may be reactivated under various conditions. Physical trauma, stress, immunosuppression, immune dysfunction and radiotherapy may trigger viral reactivation. Activation of latent herpes virus infections can cause symptomatic or asymptomatic recurrent infection, the main cause of reactivation is due to immune loss. $^{7}$

\section{Structure of herpes virus:}

The family of herpes viridae is based on a four layered structure of the virion. Herpes viruses have, a core containing a large double stranded DNA genome encased within, an icasopentahedral nucleocapsid containing 162 capsomeres, an amorphous proteinaceous tegument between envelope and capsid, a lipid bilayer envelop derived from host cell membranes, it contains surface spikes. The viral envelop contain viral-induced glycoprotein, which are ligands for cellular attachment and important targets for host immune reactions (Figure 2 ). ${ }^{8}$

Of the approximately 120 identified different herpes virus, eight major types are known to infect human namely Herpes simplex virus (HSV) type 1 and 2, Varicella - Zoster virus (VZV), E pstein - Barr virus (EBV), Human cytomegalovirus (HCMV), Human herpes Virus- 6 (HHV-6), Human herpes virus-7 (HHV-7), Human herpes virus-8 (HHV-8). Humans are the only sources of infections for these eight herpes viruses. Human herpes viruses are classified into 3 groups based on the pathogenicity, cell tropism and properties of their growth (Table 1).

\section{Types of herpes virus and associated common diseases (Table 2):}

\section{Herpes virus replication:}

Herpes virus transcription, genomereplication, and capsid assembly occur in the host cell nucleus. Herpes virus virion genes are replicated in a specific order (Figure 3): 8

(i) I mmediate-early genes, which encode regularly proteins.

(ii) Early genes, which encode enzymes for replicating viral DNA.

(iii) Late genes, which encode structural proteins of the capsid of the virion.

Virion initiates infection by fusion of the viral envelop with plasma membrane following attachment to the cell surface. Capsid is transported to the nuclear pore where viral DNA is released into the nucleus. Viral transcription and translation occur in 3 phases: immediate early, early, and late. I mmediate early proteins shut off cell protein synthesis. Early protein facilitate viral DNA replication. Late protein are structural proteins of the virus that forms empty capsids. Viral DNA is packaged into preformed capsids in the nucleus. Virion are transported via endoplasmic reticulum and released by exocytosis or cell Iysis.

\section{Prevalence of herpes viruses in periodontal health and disease:}

Periodontal health is associated with median genome detection rates of $8 \%$ for Epstein-Barr virus and for cytomegalovirus. Healthy peri-implant sites have demonstrated an absence of cytomegalovirus. Gingivitis studies reveal a median genome detection rate of $20 \%$ for Epstein- Barr virus and 33\% for cytomegalovirus. ${ }^{9}$ 


\section{Herpes virus infection associated with periodontal disease:}

Herpes virus infections generally involvea mild or asymptomatic primary phase followed by an asymptomatic latent phase inter rupted sporadically by periods of activation. Herpes virus reactivation is triggered by a number of immunosuppressing factors, some of which have also been shown to be risk indicators of periodontal disease. In periodontal disease, HCMV, EBV and HCMV-EBV co-infection are closely associated with disease-active periodontitis in juveniles and adults, with ANUG in children, and with periodontal abscesses. HCMV infects periodontal monocytes/macrophages and Tlymphocytes, and EBV infects periodontal Blymphocytes that may cause release of tissuedestructive cytokines, overgrowth of pathogenic periodontal bacteria, and initiation of cytotoxic or immunopathogenic events. ${ }^{10}$

Herpes virus-associated periodontal sites tend to harbour el evated levels of periodontopathic bacteria, including Dialister pneumosintes, Porphyromonas gingivalis, Tannerella forsythia, Prevotella intermedia, Prevotella nigrescens, Treponema denticola, Campylobacter rectus and Aggregatibacter actinomycetemcomitans. ${ }^{11-15}$ Hence data suggest periodontitis occurs more frequently and progresses more rapidly in herpes virus-infected periodontal sites.

The detection rate of periodontal herpes viruses depends on, the type of periodontal lesion studied, the viral identification method employed and ethnic - geographical factors. Higher number of herpes viruses identified in advanced periodontal disease. Because of diagnostic difficulties and a natural fluctuation in periodontal herpes viruses, most of studies have reported a wide variation in the occurrence of herpes simplex virus (13-100\%), Epstein-Barr virus (3-89\%) and cytomegal ovi rus(0.3-83\%). ${ }^{9}$

Syndromes associated with periodontal disease and possible viral etiology (Table 3): ${ }^{9}$

E vidence for a potential role of herpes viruses in the etiology of periodontal disease:2

1. Virus detection in gingival tissue.

2. Higher frequency of virus detection in the gingival tissue of periodontitis sites than in healthy sites

3. Higher frequency of herpes virus detection in GCF from periodontally diseased sites than from gingivitis/healthy sites

4. Higher frequency of virus detection in subgingival plaque from periodontally diseased than from healthy sites

5. Interaction of herpes viruses with periodontal pathogens

\section{Pathogenesis of herpes virus-associated perio- dontal disease: ${ }^{16}$}

Herpes viruses may cause periodontal pathology as a direct result of virus infection and replication, or as a result of virally mediated damage to the host defense. Herpes viruses may exert periodontopathic potential through at least five mechanisms, operating alone or in combination.

Firstly, herpes viruses may cause direct cytopathic effects on fibroblasts, keratinocytes, and endothelial cells on inflammatory cells such as polymorphonuclear leukocytes, Iymphocytes, macrophages and possibly on bone cells. Since the above cells are key constituents of inflamed periodontal tissue, herpes virus-induced cytopathic effects may hamper tissue turnover and repair.

Secondly, herpes viral periodontal infections may impair monocytes, macrophages and lymphocytes involved in host defense, thereby predisposing to microbial super infection.

Thirdly, gingival herpes virus infection may promote subgingival attachment and colonization of periodontopathic bacteria. Viral proteins expressed on eukaryotic cell membranes can act as bacterial receptors and generate new bacterial binding sites. Also, loss of virus-damaged epithelial cells can expose the basement membrane and the surface of regenerating cells, providing new sites for bacterial binding.

Fourthly, herpes viral infections can give rise to altered inflammatory mediator and cytokine responses. HCMV infection can up regulate interleukin 1-beta (I L-1â) and tumor necrosis factoralpha (TNF-á) gene expression of monocytes and macrophages. Increased production of the proinflammatory cytokines IL-1â and TNF-á by macrophages and monocytes has been associated with enhanced susceptibility to destructive periodontal disease. In turn, IL-1â and TNF-á up regulate matrix metalloproteinase, down regulate tissue inhibitors of metalloproteinase and mediate periodontal bone destruction.

Finally, herpes viruses can produce tissue 


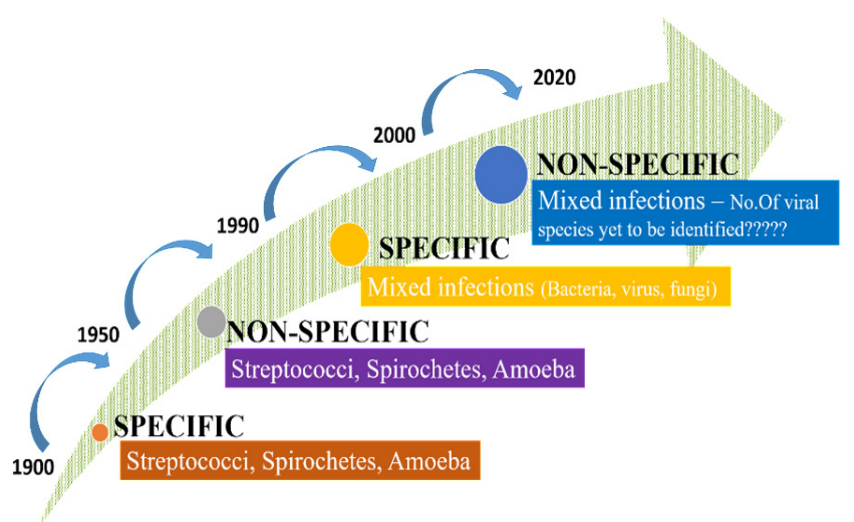

Figure 1: Hypothesis on etiology of periodontal diseases

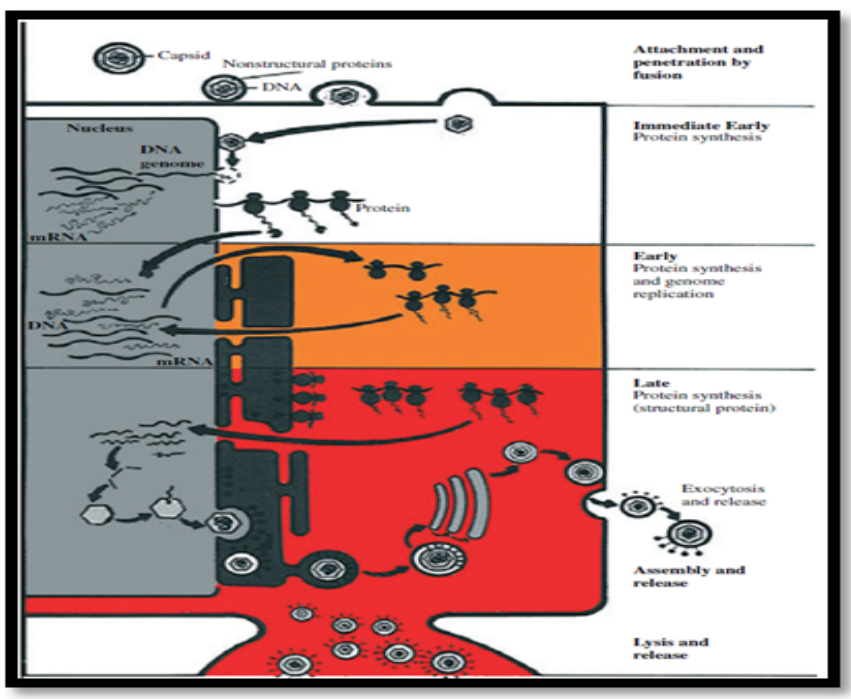

Figure 3: Herpes virus replication

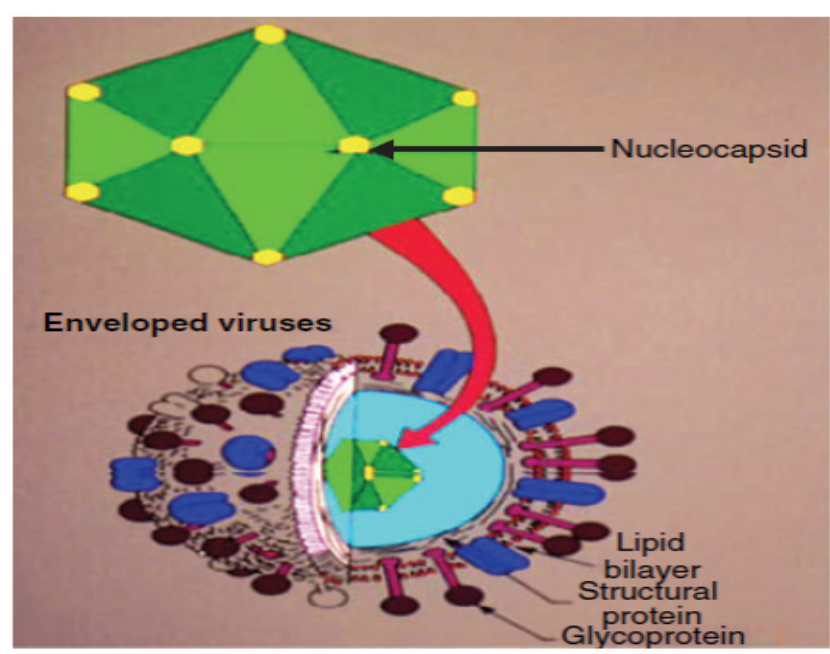

Figure 2: Structure of herpes virus

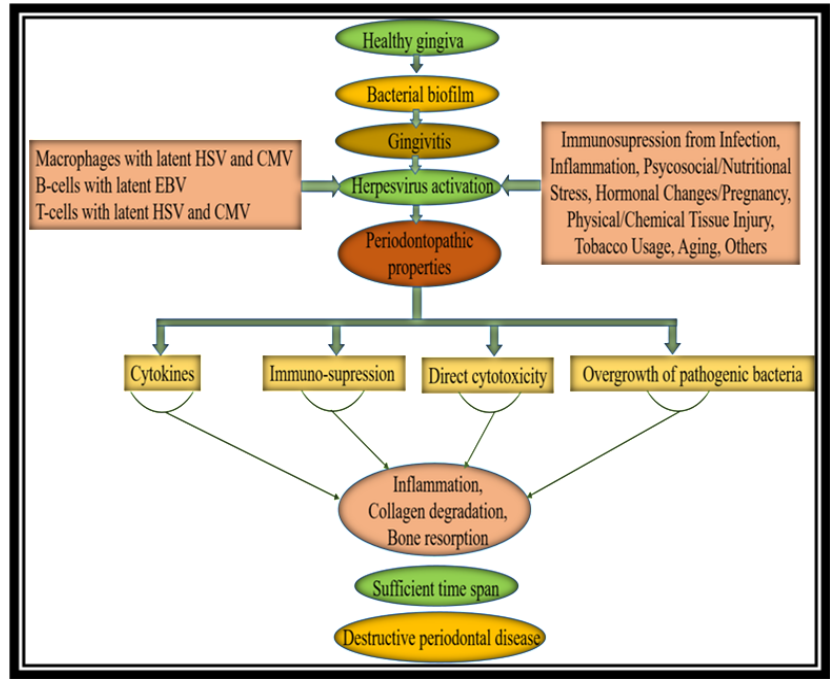

Figure 4: Herpes viral-bacterial model of periodontitis

\begin{tabular}{|c|c|c|c|}
\hline Subtypes & Type of Herpes Virus & Growth and Latency & Manifestation \\
\hline Alpha - herpes viruses & $\begin{array}{l}\mathrm{HSV}-1 \\
\mathrm{HSV}-2 \\
\mathrm{VZV}\end{array}$ & $\begin{array}{l}\text { Fast growing pattern, lyse infected } \\
\text { cells and remain latent in sensory } \\
\text { nerve ganglia. }\end{array}$ & $\begin{array}{l}\text { Vesiculous lesions in } \\
\text { skin or mucosa }\end{array}$ \\
\hline Beta-herpes viruses & $\begin{array}{l}\text { HCMV } \\
\text { HHV-6 } \\
\text { HHV-7 }\end{array}$ & $\begin{array}{l}\text { Slow replication, produce large } \\
\text { multinucleated cells remains latent in } \\
\text { lymphoreticular tissues, secretory } \\
\text { gland (i.e, salivary glands), kidneys } \\
\text { and other tissues. }\end{array}$ & $\begin{array}{l}\text { General diseases in } \\
\text { immunocompromised } \\
\text { patients. }\end{array}$ \\
\hline Gamma-herpes viruses & $\begin{array}{c}\text { EBV } \\
\text { HHV-8 }\end{array}$ & $\begin{array}{l}\text { Latency of this subfamily frequently } \\
\text { occurs in lymphoid tissues. }\end{array}$ & $\begin{array}{l}\text { EBV - Infections } \\
\text { mononucleosis and } \\
\text { HHV-8 - Kaposi's } \\
\text { sarcoma }\end{array}$ \\
\hline
\end{tabular}

Table 1: Subtypes of herpes virus 


\begin{tabular}{|c|c|c|}
\hline HUMAN HERPES VIRUSES & ABBREVIATION & MOST COMMONLY ASSOCIATED ILLNESS \\
\hline Herpes simplex virus type 1 & HSV-1 & $\begin{array}{l}\text { Acute Herpetic gingivostomatitis, Keratitis, } \\
\text { Conjunctivitis, Encephalitis, Dermal whitlow }\end{array}$ \\
\hline Herpes simplex virus type 2 & HSV-2 & Herpes genitalis \\
\hline Varicella-zoster virus & VZV & Chicken pox/shingles \\
\hline Epstein-Barr virus & EBV & $\begin{array}{l}\text { Infectious mononucleosis, Glandular fever } \\
\text { Burkitt's lymphoma, Hodgkins lymphoma, } \\
\text { Nasopharyngeal carcinoma, Squamous } \\
\text { carcinoma, Oral hairy leukoplakia, }\end{array}$ \\
\hline Cytomegalovirus & HCMV & Congentital abnormalities \\
\hline Human herpesvirus 6 & HHV-6 & Infant rash Exanthem subitum \\
\hline Human herpesvirus 7 & HHV-7 & Febrile illnesses \\
\hline Human herpesvirus 8 & HHV-8 & Kaposi's sarcoma \\
\hline
\end{tabular}

Table 2: Types of herpes virus and associated common diseases

\begin{tabular}{|l|l|}
\hline \multicolumn{1}{|c|}{ SYNDROMIE } & PERIODONTAL VIRUS \\
\hline Gullian-barre syndrome & Cytomegalovirus \\
\hline Kostmann syndrome & Epstein-barr virus \\
\hline Fanconis anemia & $\begin{array}{l}\text { Herpes simplex virus } \\
\text { Cytomegalo virus }\end{array}$ \\
\hline Papillon-lefevre syndrome & $\begin{array}{l}\text { Epstein barr virus } \\
\text { Cytomegalovirus }\end{array}$ \\
\hline Downs syndrome & Herpes simplex virus \\
& Epstein-barr virus \\
& Cytomegalo virus \\
\hline
\end{tabular}

Table 3: Syndromes associated with periodontal disease and possible viral etiology

injury as result of immune-pathological responses to virally infected cells.

\section{Herpes virus and cell mediated immunity: ${ }^{17}$}

HCMV and HSV can induce cell-mediated immunosuppression by reducing the cell surface expression of MHC (major histocompatibility complex) class I mole-cules, thereby interfering with T-lymphocyte recognition, suppress antigen-specific cytotoxic T-lymphocyte functions, resulting in decreases in circulating $\mathrm{CD} 4^{+}$cells and increases in CD8 ${ }^{+}$suppressor cells, which in turn may lead to impairment of cell-mediated immunity. EBV may trigger proliferation of cytotoxic T-lympho-cytes capable of recognizing and destroying virally infected cells. Various aspects of periodontal immune response may be hampered secondarily by EBV.

\section{Herpes viral-bacterial model of periodontitis (Figure 4): 9}

The finding of abundant herpes viruses in periodontitis lesions redefines the pathogenic paradigm of the disease. Slots and Contreras ${ }^{9}$ proposed an infectious disease model for the development of periodontitis based on herpes virusbacteria-host interactive responses. Herpes virus infection of periodontal sites may be important in a multistage pathogenesis by altering local host responses. I nitially, bacterial infection of the gingiva causes inflammatory cells to enter gingival tissue, with periodontal macrophages and T-lymphocytes harboring latent HCMV and periodontal Blymphocytes harboring latent EBV.

\section{Challenges for the hypothesis of herpes viruses being involved in the etiology of periodontal diseases: ${ }^{2}$}

1. Same group of investigators or were performed in collaboration with them.

2. Almost all samples were analyzed in the same laboratory.

3. Confirmation by other, independent researchers is lacking. 
4. Nested PCR test displays higher specificity. This technology is very susceptible to contamination, and can produce false positive results.

5. Wide range of age and the unknown origin and socioeconomic status of study population constitutes a limitation in studies comparing different populations.

6. Sampling procedure: In diseased sites, with increased probing depths and bleeding on probing, samples from diseased sites are more likely to contain viruses present in blood.

\section{Management of viral load:}

Conventional periodontal therapy can reduce the periodontal load of viruses. Mechanical debridement suppresses subgingival EBV \& CMV. 8 Mechanical debridement with systemic amoxicillin - metronidazole can suppress subgingival EBV, CMV, and Aggregatibacter actinomycetumcomitans to undetectable levels. ${ }^{18}$ Anti-H HV chemotherapy will decrease the salivary viral load. Acyclovir types of drugs areacyclic nucleosideanalogues that inhibit HHV replication. Valacyclovir, $2 \mathrm{~g}$ twice on the day of treatment and $1 \mathrm{~g}$ twice the following day, resulted in a significant decrease in the salivary occurrence of EBV. ${ }^{19}$ In a study, refractory periodontitis patients were treated with the valacyclovir 500 mg twice a day for 10 days. The treatment suppressed subgingival Epstein-Barr virus to undetectable levels for at least 1 year and resulted in clinical improvement. ${ }^{20}$

Future management of periodontal diseases may benefit from anti-viral immunotherapy: either prophylactic vaccines, which harness the immune system of healthy subjects to prevent infection with disease-causing viruses; or therapeutic vaccines, which stimulate the immune system into combating existing viruses and disease.

\section{Conclusion:}

Better understanding of etiology in periodontal disease is critical factor for diagnosis and treatment planning. Recent research described the potential role of viral-bacterial interactions in pathogenesis of periodontal disease. Further research is required to confirm the etiological role of viruses in periodontal disease and development of new vaccines for the prevention of periodontal disease is a futuristic goal.

\section{References}

1. Slots J . Herpes viruses in periodontal diseases. Periodontol 2000, 2005; 38:33-62.

2. Cappuyns I, Gugerli P, Mombelli A. Viruses in periodontal disease - a review. Oral Dis 2005; 11:219-29.

3. Spriggs MK. One step ahead of the game: viral immunomodulatory molecules. Annu Rev Immunol 1996; 14:101-30.

4. Kolliyavar B, Shetty S, Patil A, Thakur SL. Association of viruses in chronic periodontitis- fact or hype?? Intl J Oral Hyg Dent Res 2013; 1(1):1-5.

5. Contreras A, Slots J. Mammalian viruses in human periodontitis. Oral Microbiol Immunol1996; 11(6):381-6.

6. Parra B, Slots J. Detection of human viruses in periodontal pockets using polymerase chain reaction. Oral Microbiol Immunol 1996; 11(5):289-93.

7. Roizmann B, Desrosiers RC, Fleckenstein B, Lopez C, Minson AC, Studdert MJ (1992). The family Herpesviridae: an update. The Herpes virus Study Group of the International Committee on Taxonomy of Viruses. Arch Virol 123:425-49.

8. Slots J. Herpes viral-bacterial interactions in periodontal diseases. Periodontol 2000 2010; 52:117-40

9. Slots J. Human viruses in periodontitis Periodontol 2000 2010; 53:89-110.

10. Slots J . Herpes viruses, the missing link between gingivitis and periodontitis? J Int Acad Periodontol 2004; 6(4):113-9.

11. Slots J, Kamma JJ, Sugar C. The herpes virusPorphyromonas gingivalis-periodontitis axis. J Periodontal Res 2003; 38:318-23.

12. Saygun I, Kubar A, zdemir A, Yapar M, Slots J. Herpesviralbacterial interrelationships in aggressive periodontitis. J Periodontal Res 2004; 39:207-12.

13. Contreras A, Umeda M, Chen C, Bakker I, Morrison J L, Slots J. Relationship between herpesviruses and adult periodontitis and periodontopathic bacteria. J Periodontol 1999; 70:478-84.

14. Slots J , Sugar C, Kamma J J . Cytomegal ovirus periodontal presence is associated with subgingival Dialister pneumosintes and alveolar bone loss. Oral Microbiol Immunol 2002; 17:369-74.

15. Ting $M$, Contreras $A$, Slots J. Herpesviruses in localized juvenile periodontitis. J Periodontal Res 2000; 35:17-25.

16. Contreras A, Slots J : Herpesviruses in human periodontal disease. J Periodont Res 2000; 35:3-16.

17. Azodo CC, Erhabor P. The roles of viruses in periodontal diseases. J Dent Res Rev 2015; 2:37-41.

18. Pacheco J J, Coel ho C, Salazar F, Contreras A, Slots J, Velazco CH. Treatment of Papillon-Lefe'vre syndrome periodontitis. J Clin Periodontol 2002; 29:370-4.

19. Cox AJ , Gleeson M, Pyne DB, Saunders PU, Clancy RL, Fricker PA. Valtrex therapy for Epstein-Barr virus reactivation and upper respiratory symptoms in elite runners. Med Sci Sports Exerc 2004; 36:1104-10.

20. Sunde PT, Olsen I, Enersen M, Grinde B. Patient with severe periodontitis and subgingival Epstein-Barr virus treated with antiviral therapy. J Clin Virol 2008; 42: 176-8. 